\title{
Article
}

\section{The rational use of fillet welds and butt-fillet welds in welded structures}

\author{
Kwiryn Wojsyk ${ }^{1}$, Krzysztof Kudła ${ }^{1, *}$ \\ ${ }^{1}$ Czestochowa University of Technology \\ Kwiryn Wojsyk, Ph.D. Eng., kwiryn@gmail.com \\ * Correspondence: Krzysztof Kudła, Ph.D. Eng., kudla@itm.pcz.pl
}

Received: 25.03.2019; Accepted: 01.06.2019

\begin{abstract}
The study contains quantitative conditions and limitations of the use of butt, fillet and butt-fillet welds in modern welded constructions. Examples of improper use are given. Calculated loss of material and capacity structures associated with the use of fillet welds with a convex face, their asymmetry, as well as the benefits of in-depth penetration obtained by hybrid (plasma-MAG, laser-MAG) or other, leading to the achievement of butt welds and butt-fillet welds with high-efficiency welding technologies. A list of the requirements for the correct use of fillet welds and features differing from butt, butt-fillet and fillet welds is given.
\end{abstract}

Key words: fillet welds; butt welds; butt-fillet welds; welding distortions; strength of welded joints

\section{Introduction}

Welded constructions usually consist of joints made with two types of welds: fillet welds, whose share in constructions reaches even $90 \%$ and butt welds. These proportions result from the ease of making fillet welds, the lack of necessity of bevelling the materials, the lower qualifications of welders and the dominant share of mutually perpendicular combinations of sheets and profiles to obtain a lattice, openwork or box shape of the structure. Such a significant share of fillet welds in the construction of various types of structures resulted in the separation of welding permits in EN ISO 9606-1:2014-02: the first qualification stage includes the possibility of welding only fillet welds, while the next - butt welds of sheets and pipes. This division is perpetuated by the constant lack of highly qualified welders who should first master lower skills and then perform more responsible butt welds. In contrast to manual welding (e.g. MMA) or partially mechanized (e.g. MIG/MAG), robotic and automated welding requires only the training of operators in accordance with EN ISO 9606-1:2014-02 and EN ISO 14732:2014, and the quality of the welds obtained depends mainly on the setting and maintenance of the assumed welding parameters. In addition, after the robots are connected to the periphery (e.g. positioners) welding is carried out almost exclusively in the flat (PA) or lateral (PB) position, which in turn allows the use of higher current-voltage parameters leading to deep penetration of the welds. This way we achieve the combination of the advantages of welding resulting from the possibility of non-chamfered even thick elements of angular, T-shaped and cross joints to achieve the butt welds or butt-fillet welds (EN 1993-1-8: 2006 Eurokod 3 part 1:8).

These possibilities are a derivative of the application of new variations of the MAG process in the field of high performance welding without arc rotation and hybrid welding (laser-MAG, plasma-MAG). It is paradoxical to recognize in PN-EN 1993-1-8: 2006 welds with incomplete penetration, i.e. with two notches in ridges, as full-fledged, provided only the following conditions are met (Fig. 1). Butt-fillet welds take over the characteristics of both butt welds and fillet welds:

- the thickness of the butt-fillet welds and butt welds $a_{s p}$ can reach the thickness of the joined material $t_{\min }$ (Fig. 1)

and

$$
a_{s p}=a_{n o m 1}+a_{\text {nom } 2} \geq t_{\text {min }}
$$

$$
\begin{gathered}
c_{\text {nom }} \leq \frac{t_{\min }}{5} \quad \text { and } \quad c_{\text {nom }} \leq 3 \mathrm{~mm} \\
a_{s p}=t_{\min }
\end{gathered}
$$




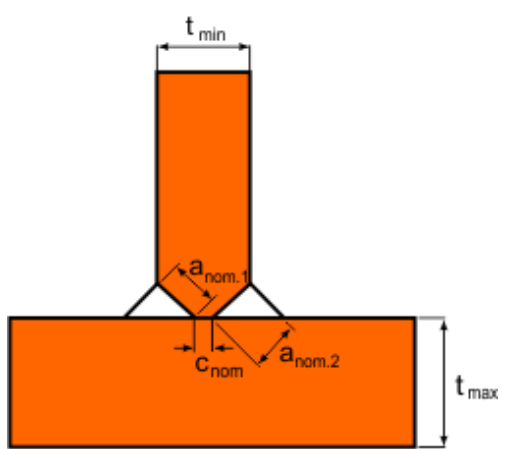

Fig. 1. Effective full penetration in T-joint with butt weld acc. EN 1993-1-8:2006

Fig. 2. Thickness of fillet welds $a$
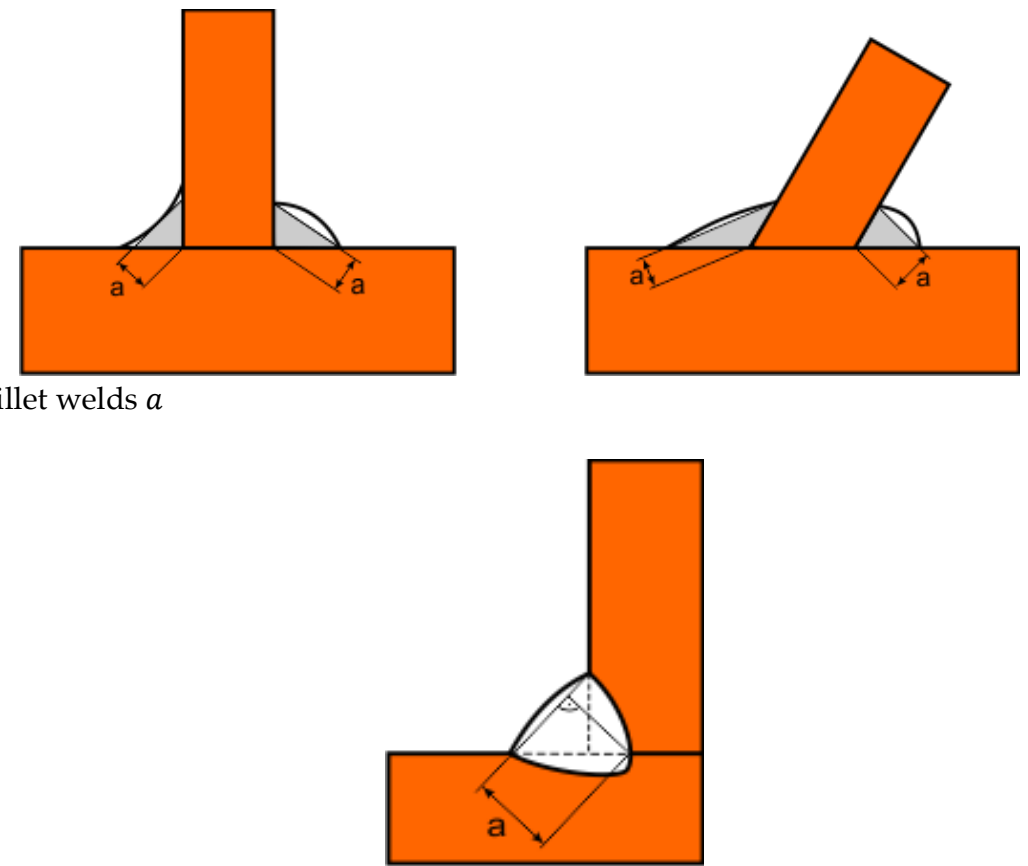

Fig. 3. Thickness of fillet weld $a$ with deep penetration

- may require bevelling of welded materials;

- the face can be flat or concave;

- they are designed for joining thick elements, which are not loaded with vibrations due to the lack of full penetration (notch in the ridge);

- can be enlarged "inwards", provided that technological control of the penetration depth is ensured and increase the volume of the structure;

- the occurrence of notch and the presence of gases in their ridge is inevitable;

- they may have the length of combined materials or they do not meet this condition.

Butt welds differ from the fillet ones with several features that can generally be classified as follows [1-3]:

\begin{tabular}{|c|c|}
\hline Butt welds & Fillet welds \\
\hline $\begin{array}{l}\text { Practically, they always have a thickness } \\
\text { of combined materials, possibly a thinner one } \\
\text { (except for butt joints with incomplete } \\
\text { penetration allowed by Eurocode 3). }\end{array}$ & $\begin{array}{l}\text { Properly designed and made, they never reach the thickness } \\
\text { of the materials being combined, within the limits (above } 3 \mathrm{~mm} \text { ): } \\
\qquad t_{s p}>0.2 t_{\text {max }} \text {, } \\
\qquad t_{s p} \leq 0.7 t_{\min } \text { for one-sided welds, } \\
t_{s p} \leq 0.5 t_{\min } \text { for double-sided welds. } \\
\text { When it comes to welding hot-rolled } \\
\text { sections, these values are } 0.6 \mathrm{t} \text { and } 0.8 \mathrm{t} \text {, } \\
\text { respectively: }\end{array}$ \\
\hline
\end{tabular}




\begin{tabular}{|c|c|}
\hline $\begin{array}{c}\text { Above a certain thickness-specific welding } \\
\text { method, joints must be assembled from bevelled } \\
\text { materials. }\end{array}$ & They do not require bevelling of welded materials. \\
\hline Should have a flat or slightly convex face. & $\begin{array}{l}\text { The convex face is always unfavourable, both for strength } \\
\text { and economic reasons. } \\
\text { The most preferred is the concave face, and the accepted - flat. }\end{array}$ \\
\hline They do not increase the volume of the structure. & They increase the volume of the structure. \\
\hline They are designed for carrying main loads. & $\begin{array}{l}\text { Designed for connecting weakly loaded components } \\
\text { and those not subjected to vibratory loads. }\end{array}$ \\
\hline $\begin{array}{l}\text { Their cross-section is defined by the thickness } \\
\text { of the elements, and its reduction is possible by } \\
\text { using methods with the use of a high-density arc. }\end{array}$ & $\begin{array}{l}\text { They can be enlarged "inwards" provided that this fact } \\
\text { is documented. By using deep welding welding methods, } \\
\text { the thickness of fillet welds can be increased } \\
\text { according to EN 1993-1-8: } 2006 \text {. }\end{array}$ \\
\hline $\begin{array}{l}\text { Ease of non-destructive inspection and the ability } \\
\text { to obtain ridges of welds with high strength } \\
\text { parameters (except for butt welds with } \\
\text { incomplete penetration). }\end{array}$ & $\begin{array}{l}\text { Both in the case of one-sided and double-sided welds, there } \\
\text { is a limited possibility of controlling the existence and quality } \\
\text { of the penetration, which may lead to the presence of notches } \\
\text { in the ridge and initiators of cracks. }\end{array}$ \\
\hline $\begin{array}{l}\text { The length of the weld is always equal } \\
\text { to the length of the joined materials. }\end{array}$ & $\begin{array}{l}\text { The calculated length of the weld is not rigidly related } \\
\text { to the length of the elements. There are intermittent beads. } \\
\text { The length of individual sections of fillet welds is between } 6 a_{s p} \\
\text { and } 150 a_{s p} \text { ( } a_{s p} \text { - calculated joint thickness), however not less } \\
\text { than } 30 \mathrm{~mm} \text {. Above } 150 a_{s p} \text { or } 1.7 \mathrm{~m} \text {, the welds have lower design } \\
\text { strength. }\end{array}$ \\
\hline
\end{tabular}

During automated or robotic welding and the use of deeply fusing methods [2], the above weld features can be used, bringing fillet welds to the butt-fillet or butt ones, which reduces the volume and mass of the structure, consumption of additional materials, as well as the size of welding angular deformations leading to the construction in higher accuracy classes (Fig. 4).

The property of modern welded constructions is not only the oversizing of welds, i.e. the use of oversized thick joins in relation to the used thicknesses of bonded materials and necessary needs, but also in spite of the requirements in the relevant standards of excessive approaching in the corners and on both sides of the welded elements so that they are exposed to stretching on its thickness.

In addition, the constructors do not differentiate between the load-bearing and joint functions of the welds, thus they do not differentiate their thickness, which unnecessarily introduces excessive stresses and final deformations. The principle that construction materials transfer loads, not welds connecting them

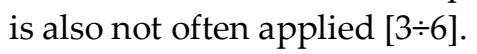

The most common mistake at present is the use of fillet welds equal to material thickness by constructors with double-sided welds $a_{s p}=0,5 t_{\min }$ or $a_{s p}=0,7 t_{\min }$ with one-sided welds, while these are the maximum values. It is not possible to take into account the depth of penetration in the dimensioning of fillet welds and to bring them to the butt-fillet or butt joints.

When reviewing the solutions of modern welded constructions, one gets the impression that the fillet welds used in them are not individually designed and arranged but assumed and executed without taking into account the real construction and strength requirement.

Meanwhile, proper understanding of the impact of welds on structures can reduce not only their costs, but also reduce the final state of stress and deformation, and thus improve the accuracy of performance, strength and operational safety of the welded structure. In order to understand the effect of a fillet weld in a construction, several of its features should be considered:

\section{- The fillet weld volume and its strength}

The volume of a symmetrical fillet weld is:

$$
V_{s p}=a_{s p}^{2} l
$$

The strength of this weld is proportional to the area of the cross-section:

$$
F_{s p}=a_{s p} l
$$



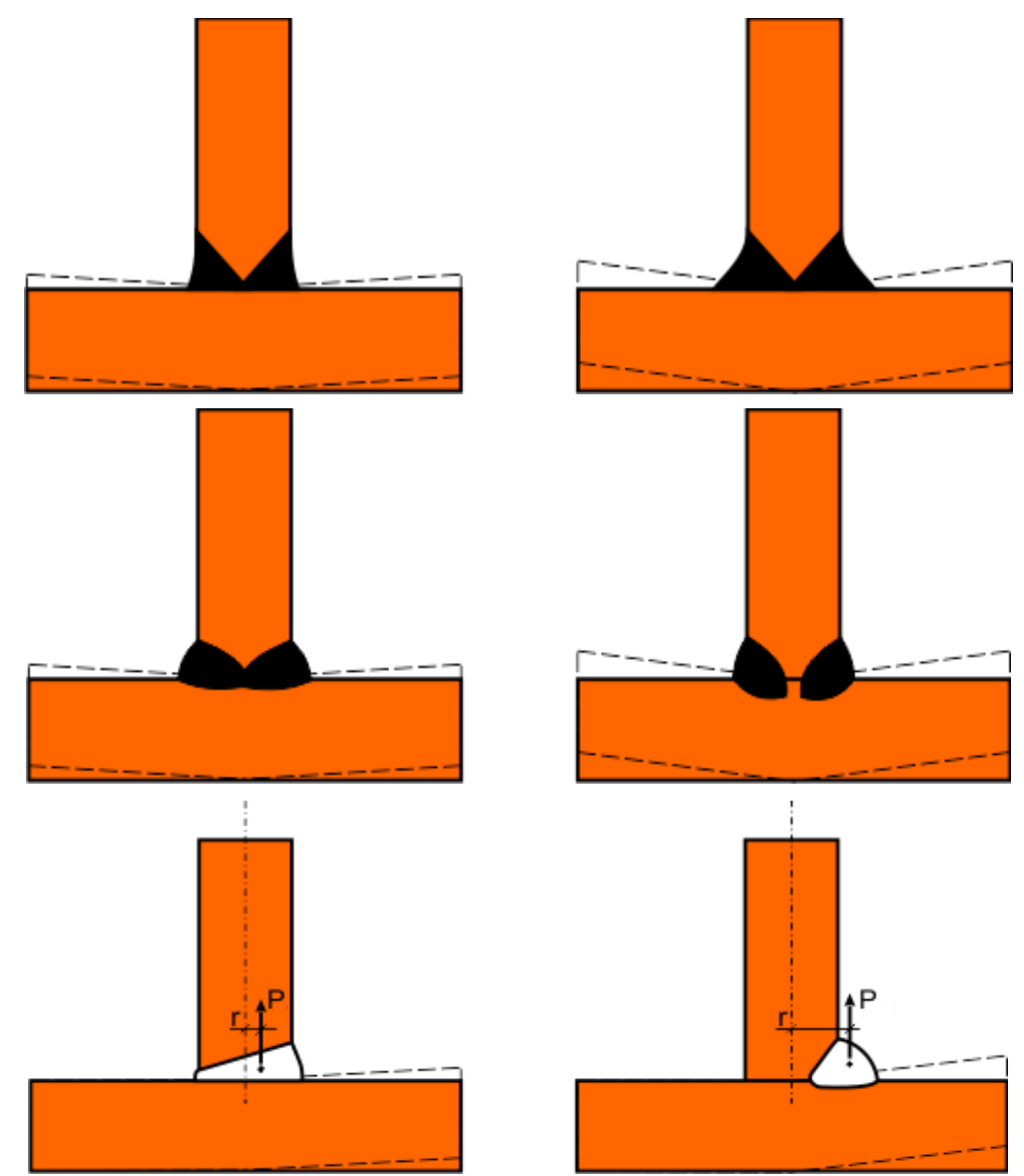

Fig. 4. Illustration of the formation of angular distortion in $\mathrm{T}$-joints connected with various types of welds (P - force causing joint deformation, $\mathrm{r}-$ arm of force $\mathrm{P}$ between the neutral axis and the mass centre of the weld cross-section)

The above equations show that the weld volume increases in proportion to the square of the thickness, and the strength to the thickness of the fillet weld, and thus much slower (Fig. 5).

This simple analysis clearly shows that the use of thick fillet welds is not profitable and taking into account deeper penetration in strength calculations gives an additional benefit by introducing the weld into the interconnected materials. The volume and weight of the structure do not increase, but the load capacity compensation is not sufficient. Also, the consumption of additional materials and welding time can be significantly reduced.

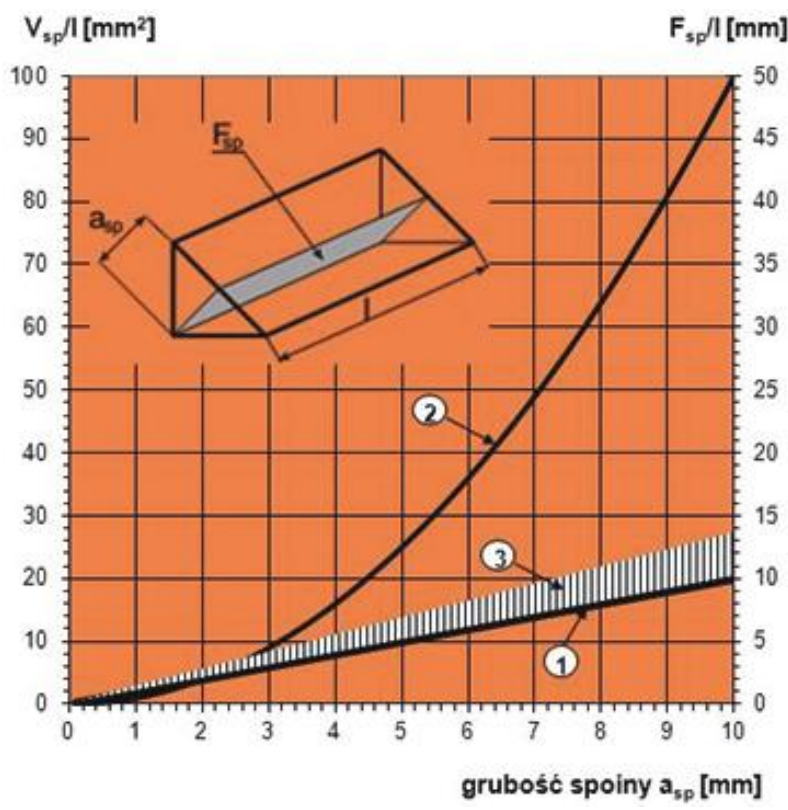

Fig. 5. Difference of strength increase (1) and volume (2) of symmetrical fillet weld with flat surface (3) - the area of possible increase in strength due to the increased penetration allowed by the standard EN 1993-1-8:2006 
- Loss of material related to the convexity of the fillet face

If the cylindrical shape of the face is assumed and the height of the ridge should be as much as the weld thickness, then the material loss for the unusable part of the fillet weld, contributing additionally to the shape notches, can be presented as in Table I and figure 6 .

Table I. Useless volume (NO) of fillet weld depending on the ratio $\frac{h}{a_{s p}}$

\begin{tabular}{cccccc}
\hline$\frac{\boldsymbol{h}}{\boldsymbol{a}_{\boldsymbol{s p}}}$ & $\mathbf{0 . 1}$ & $\mathbf{0 . 2}$ & $\mathbf{0 . 3}$ & $\mathbf{0 . 4}$ & $\mathbf{0 . 5}$ \\
\hline $\mathrm{NO}[\%]$ & 13 & 27 & 40 & 53 & 67 \\
\hline
\end{tabular}

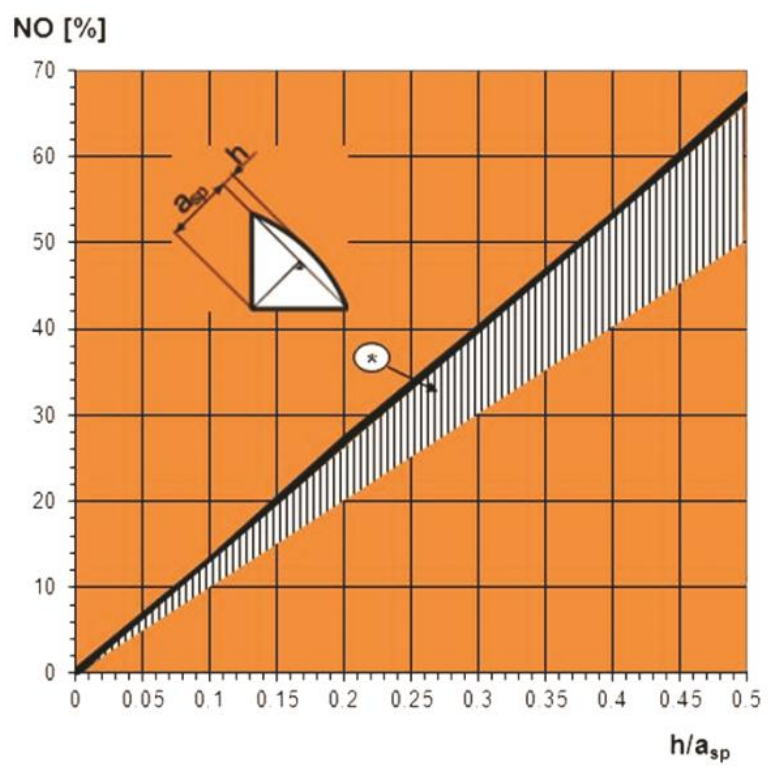

Fig. 6. The share of the inactive (useless) volume of the weld depending on the ratio $\frac{h}{a_{s p}}$

* the area under the straight line means that there is a possibility of obtaining a more favorable ratio if deep welding methods are used and confirmed technologically

\section{- Loss of material due to the asymmetry of fillet weld}

The calculation assumptions of Eurocode 3 EN 1993-1-8: 2006 and [7,8] allow to calculate the strength of asymmetrical fillet welds. However, their use is not effective, because the higher the asymmetry of the weld occurs, the greater the disproportion between the load capacity of the symmetrical and asymmetrical weld (Fig. 7):

$$
S_{s p}^{a s}=\frac{a_{s p}^{2}}{\sin 2 \alpha}
$$

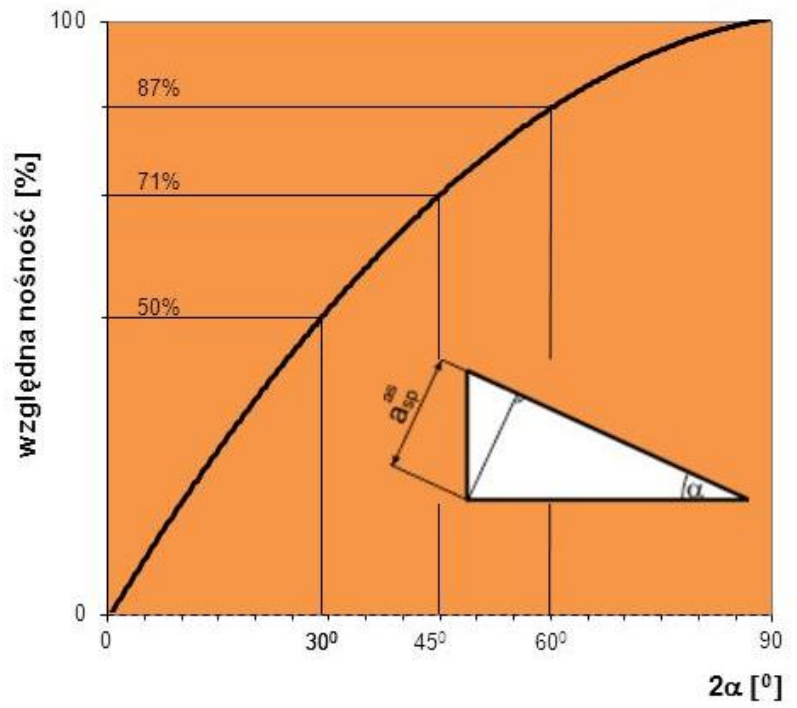

Fig. 7. The relative load capacity of the asymmetrical weld in relation to the symmetrical weld 
(Table II).

The presence of the riser leads to even greater material losses than in the case of symmetrical welds

Table II. Useless volume (NOas) of the asymmetrical fillet weld depending on the ratio $\frac{h}{a_{s p}}$ and the angle $\alpha$

\begin{tabular}{cccccccc}
\hline & & \multicolumn{2}{c}{$\frac{\boldsymbol{h}}{\boldsymbol{a}_{\boldsymbol{s p}}}$} & & & & \\
$\boldsymbol{\alpha}$ & $\mathbf{0}$ & $\mathbf{0 . 1}$ & $\mathbf{0 . 2}$ & $\mathbf{0 . 3}$ & $\mathbf{0 . 4}$ & $\mathbf{0 . 5}$ \\
\hline $15^{\circ}$ & $100 \%$ & $127 \%$ & $153 \%$ & $180 \%$ & $207 \%$ & $233 \%$ \\
$22^{\circ} 30^{\prime}$ & $41 \%$ & $60 \%$ & $79 \%$ & $97 \%$ & $117 \%$ & $135 \%$ \\
$30^{\circ}$ & $15 \%$ & $31 \%$ & $46 \%$ & $62 \%$ & $77 \%$ & $92 \%$ \\
$45^{\circ}$ & $0 \%$ & $13 \%$ & $27 \%$ & $40 \%$ & $53 \%$ & $67 \%$ \\
\hline
\end{tabular}

Thus, it can be concluded that with the same fillet weld thickness ( $\left.a_{s p}\right)$, the smallest cross-sectional area, and therefore the volume ( $S_{s p}=a^{2}$ and $V_{s p}=a^{2} l$ respectively) is obtained for a flat isosceles weld (without riser). The higher the asymmetry of the weld and the higher the riser, the time, material and energy losses for welding are higher [8-11]. This is accompanied not only by the increase of undesirable deformations of the structure, but also by the creation of concentration of stresses that may cause the critical values to be exceeded, the achievement of fragile states of combined materials, and, as a result, the development of cracks [12-17]. The guiding principle of effective use of fillet welds should be to guarantee their smooth transitions to combined materials. The use of methods characterized by deep penetration can lead to the elimination of the critical part of these welds - the ridge, by achieving penetration into the previously made weld in the welded joints. Many studies indicate a significant effect of the lack of full penetration or similar incompatibilities forming an internal or external shape notch on a radical reduction of the mechanical properties of joints $[18 \div 22]$.

\section{Summary}

The conditions of using fillet welds in welded constructions can be included in the following points:

1. Use materials with good weldability.

2. Minimize the number and volume of welds.

3. Do not place welds in the most strenuous places.

4. Use butt welds and then fillet welds.

5. Use support ribs and diaphragms to relieve welds.

6. Fillet welds should be symmetrical, thin and long (instead of thick and short) with a flat or concave face.

7. The design length of fillet welds should be between $6 a_{s p}$ or $30 \mathrm{~mm}$ and $150 a_{s}$ or $1.7 \mathrm{~m}$. Above these lengths it is necessary to apply strength correction factors.

8. The thickness of fillet welds equal to $a_{s p} \leq 0,7 t_{\min }$ for one-sided welds and $a_{s p} \leq 0,5 t_{\min }$ for double-sided welds and $a_{s p} \geq 0,2 t_{\max }$, respectively, must not be exceeded.

9. Do not arrange fillet welds in the corners of the structure, using ribs so that joints do not approach a distance of less than $30 \mathrm{~mm}$. Avoid multidirectional convergence of welds.

10. Reduce the number of welds made in forced and assembly positions.

11. Arrange the fillet welds in such a way that they do not tear the materials (sheets and rolled profiles) on their thicknesses.

12. When making multilayer joints, avoid igniting the arc in the same places.

13. Avoid welding near corners, internal arches of hot-rolled sections, edges, threads, surfaces treated accurately, heat-treated and thermo-chemically treated.

14. Avoid (with few exceptions) the use of any intermediary elements, such as overlays and inserts or connectors.

15. Use automated and robotic deep penetration methods for both butt welds and fillet welds.

16. If possible, use intermittent stitches in structures which are not exposed to corrosion and vibration loads.

17. Place welds in technologically easily accessible places.

18. Place welds at points, neutral axes or in their vicinity.

Conflicts of Interest: The authors declare no conflict of interest. 


\section{References}

[1] Kudła K., Wojsyk K., Economical use of welds in welded. Structure. XVIII Scientific and Technical Conference: Development, innovations and quality requirements for joining processes, Poland, Międzyzdroje, 22-24 May 2012.

[2] Eureka Project E!II/PL-IL/05/03/2013: Robotic welding using a new generation hybrid system based on the concept of Super-Heavy Duty (SHD) Super-MIGA®-RobWeld Super-MIGA®.

[3] Augustyn J., Śledziewski E., Failures of steel constructions, Arkady Warszawa 1976.

[4] Kudła K., Wojsyk K., Joint and strenght functions of welds in modern welded structures. Spajanie, 2010, 3(9)-4(10), 26-28.

[5] Plewniak J., Wojsyk K., The usefulness of welding structures from interpenetrating closed profiles. Welding Technology Review, 2009, Vol. 81(10), 73-76.

[6] Skarbiński M., Skarbiński M., Producibility machine construction, WNT Warsaw 1982.

[7] Wichtowski B., Calculation of static and fatigue load capacity of welds in eurocode 3. Welding Technology Review, 2011, Vol. 83(1), 15-22. [CrossRef]

[8] Nawrocki J., Słania J., The simulation of the stress field of welded joint containing the discontinuities No 1014. Welding Technology Review, 2019, Vol. 91(1), 26-31. [CrossRef]

[9] Adamiec J., Cracking of welded membrane walls during operation. Welding Technology Review, 2018, Vol. 90(4), 34-38. [Crossref]

[10] Czuchryj J., Fatigue life of joints welded on steel backing strip with large gap between joined edges. Welding Technology Review, 2017, Vol. 89(11), 43-48. [CrossRef]

[11] Mikkola E., Murakami Y., Marquis G., Fatigue life assesment of welded joints by the equivalent crack length method. Proccedia Materials Science, 2014, Vol. 3, 1822-1827. [CrossRef]

[12] Tso-Liang T., Chin-Ping F., Peng-Hsiang C., Wei-Chun Y., Analysis of residua stresses and distorions in T-joins fillet welds. International Journal of Presure Vessels and Piping, 2001, Vol. 78(8), 523-538. [CrossRef]

[13] Barsoum Z., Lundback A., Simplified FE welding simulation of fillet welds - 3D effects on the dormation residua stress. Engineering Failure Analysis, 2009, Vol. 16(7), 2281-2289. [CrossRef]

[14] Miazga G. S., Kennedy D. J., Behaviour of fillet welds as a function of the angle of loading. Canadian Journal of Civil Engineering, 1989, Vol. 16(4), 583-599. [CrossRef]

[15] Lu Yang, Yao Cui, Xuan Wei, Mengyue Li, Youzhen Zhang, Strength of duplex stainless steel fillet welded connections. Journal of Constructional Steel, 2019, Vol. 152, 246-260. [CrossRef]

[16] Torabian S., Xiao F., Haws R. B., Schafer B. W., Design of transverse fillet welds in the lapped joints of thin steel plates. International Journal of Steel Structures. 2018, Vol. 18(1), 337-348. [CrossRef]

[17] Dundu M., Mathematical model to determine the weld resistance factor of asymmetrical strength results. Structures, 2917, Vol. 12, 298-305. [CrossRef]

[18] Grimsmo E. L., Daehli L. E., Hopperstad O. S., Aalberg A., Langseth M., Clausen A. H., Numerical study of fillet welds subjected to quasi-static and impact loading. Sciences, 2017, Vol. 131-132, 1092-1105. [CrossRef]

[19] Khurshid M., Barsoum Z., Mumtaz N. A., Ultimate strenght and failure modes for fillet welds in high strength steels. Materials \& Design, 2012, Vol. 40, 36-42. [CrossRef]

[20] Mellora B. G., Rainey R. C. T., Kirk N. E., The static strenght of end and T fillet weld. Materials \& Design, 1999, Vol. 20(4), 193-205. [CrossRef]

[21] Perić M., Tonković Z., Rodić A., Surjak M., Garasić I., Boras I., Svaić S., Numerical analysis and experimental investigation of welding residua stresses and distortions in a T-joint fillet weld. Materials $\mathcal{E}$ Design, 2014, Vol. 53, 1052-1063. [CrossRef]

[22] Swannell P., Rational design of fillet weld groups. Journal of the Structural Division, 1981, Vol. 107(5), $789-802$. [Hyperlink]

(C) 2019 by the authors. Submitted for possible open access publication under the terms and conditions of the Creative Commons Attribution (CC BY) license (http://creativecommons.org/licenses/by/4.0/). 